\title{
Deciphering the structural network that confers stability to high internal phase Pickering emulsions by crosslinked soy protein microgels and their in vitro digestion profiles
}

\author{
Jiayu Wen ${ }^{1 \S}$, Yan Zhang ${ }^{2 \S}$, Hainan Jin ${ }^{1}$, Xiaonan Sui ${ }^{* *}$, Lianzhou Jiang ${ }^{1 *}$ \\ ${ }^{1}$ College of Food Science, Northeast Agricultural University, Harbin 150030, \\ China \\ ${ }^{2}$ College of Horticulture and Landscape Architecture, Northeast Agricultural \\ University, Harbin 150030, China
}

*To whom correspondence should be addressed.

$$
\begin{aligned}
& \text { Tel.: +86 } 45155190716 \\
& \text { Fax: +86 } 45155190716
\end{aligned}
$$

§The first two authors contributed equally.

Email: xiaonan.sui@neau.edu.cn (Prof. Xiaonan Sui)

jlzname@163.com (Prof. Lianzhou Jiang) 

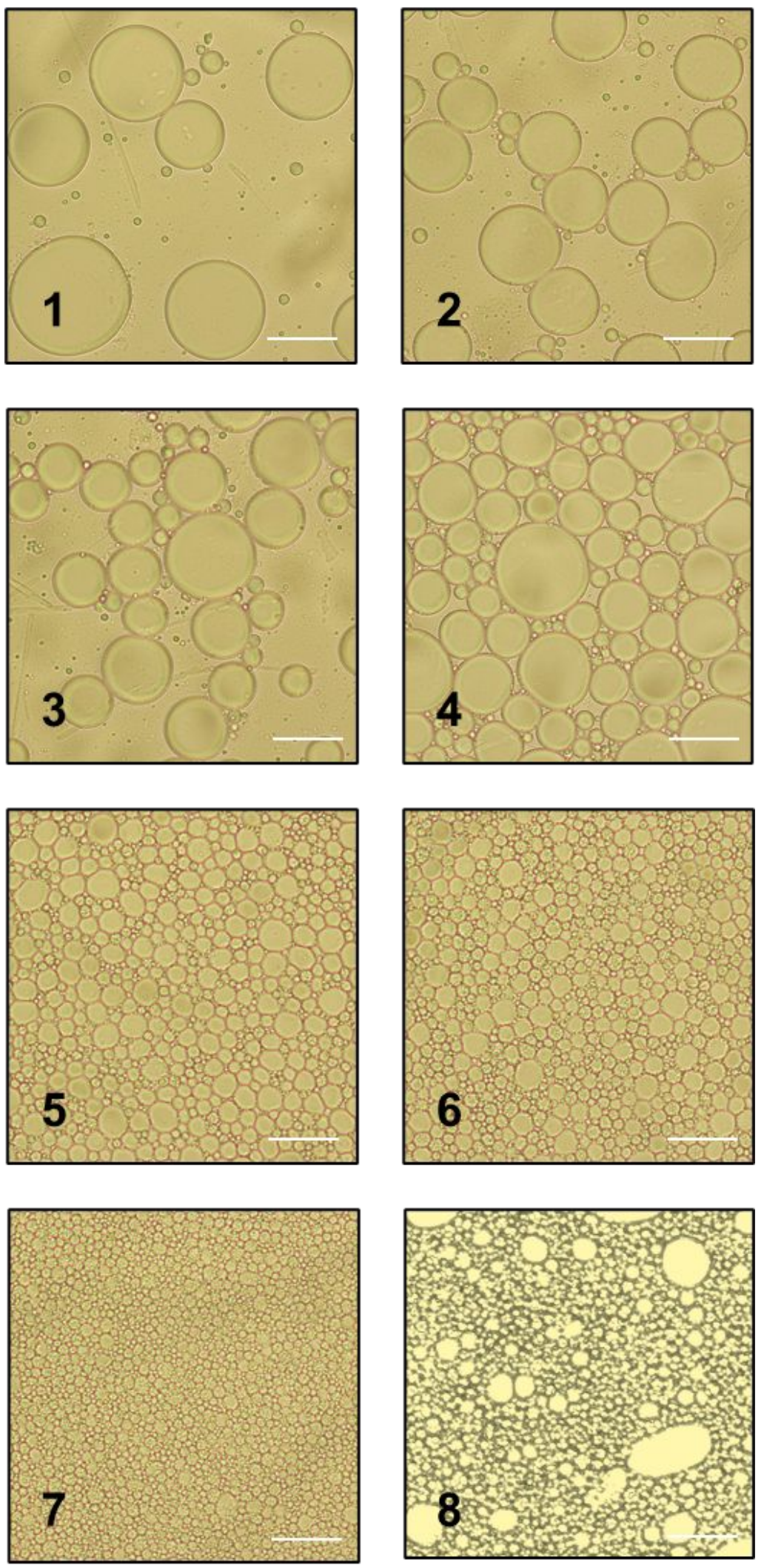

Figure S1. Optical microscopy observation of the emulsion and HIPPEs (protein conc. $1.75 \mathrm{wt} \%$ ) at $\mathrm{pH}$ of 9.0, with different oil volume fractions of $0.10-0.84$. Scale bar equals to $20 \mu \mathrm{m}$. 